\title{
FORMAÇÃO DE
}

NOVAS GERAÇÕES

NOS MUSEUS

UNIVERSITÁRIOS:

O PAPEL DO EDUCATIVO DO MUSEU DE ARQUEOLOGIA E ETNOLOGIA DA USP

MAURÍCIO ANDRÉ DA SILVA, UNIVERSIDADE DE SÃO PAULO, SÃO PAULO,

SÃO PAULO, BRASIL

Educador, Arqueólogo e responsável pelo Educativo do Museu de Arqueologia e

Etnologia da Universidade de São Paulo (MAE-USP). Doutorando do Programa de

Pós-Graduação em Arqueologia e mestre em Arqueologia, ambos pelo MAE-USP.

Bacharel e licenciado em História pela USP.

E-mail: mauricio.andre.silva@usp.br

ORCID: https://orcid.org/0000-0002-4325-9480

RECEBIDO

DOI

29/07/2020

APROVADO

http://dx.doi.org/10.11606/issn.1980-4466.v15i30p294-320

$26 / 11 / 2020$ 


\section{FORMAÇÃO DE NOVAS GERAÇÕES NOS MUSEUS UNIVERSITÁRIOS: O PAPEL DO EDUCATIVO DO MUSEU DE ARQUEOLOGIA E ETNOLOGIA DA USP}

MAURÍCIO ANDRÉ DA SILVA

\section{RESUMO}

Neste artigo, discute-se a contribuição do Educativo do Museu de Arqueologia e Etnologia da Universidade de São Paulo na formação de novas gerações para o campo museal e áreas correlatas. A instituição, ao longo de décadas, tem sensibilizado profissionais por meio do ensino, da pesquisa e da extensão. Os museus universitários, nessa perspectiva, têm atuação crucial ao ampliar o vínculo da universidade com a sociedade, especialmente com os trabalhos educacionais para o público em geral. Com o crescimento do acesso de distintas parcelas da população ao espaço universitário nos últimos anos, os museus podem ser um local privilegiado para o acolhimento dessas diferenças e para sua incorporação no mundo da ciência e da museologia. Muitos e muitas profissionais que hoje atuam em diferentes segmentos da área do patrimônio cultural começaram sua vida profissional nesses locais, em particular dentro das universidades públicas.

PALAVRAS-CHAVE

Educação em museus, Estágios, Museus arqueológicos, Museus universitários. 


\title{
TRAINING NEW GENERATIONS IN UNIVERSITY MUSEUMS: THE ROLE OF EDUCATION IN THE ARCHEOLOGY AND ETHNOLOGY MUSEUM OF THE UNIVERSITY OF SÃO PAULO
}

\author{
MAURÍCIO ANDRÉ DA SILVA
}

\section{ABSTRACT}

This paper discusses the contribution of the Education Department of the Museum of Archeology and Ethnology of the University of São Paulo to the professional development of students in museology and related areas. For decades, the institution has impacted professionals through education, research, and extension programs. University museums, in this perspective, play a crucial role in deepening the university's ties with local and regional communities, especially through education programs aimed at the general public. As more distinct portions of the population have had access to higher education in recent years, museums can be a privileged domain for welcoming social differences and incorporating them into the realm of science and museology. Many of those who currently operate in different segments of the cultural heritage sector began their professional life in these institutions, especially within public universities.

KEYWORDS

Education in museums, Internships, Archeological museums, University museums. 


\section{INTRODUÇÃO}

Os museus universitários têm uma longa tradição na formação de gerações para os campos museal e científico, e para as demais áreas que envolvem seus acervos. No contexto brasileiro, estão ancorados no princípio da indissociabilidade do ensino, pesquisa e extensão das universidades, garantido pela Constituição de 1988, que proporciona um lócus ideal para a aprendizagem continuada e para atuação na sociedade. Esses museus são a porta de entrada para muitos(as) jovens, o que possibilita a transformação e a renovação da área. Existe uma variedade de formatos e de modelos de museus universitários com múltiplas configurações institucionais, que vão de instituições com equipe especializada em seus quadros funcionais a coleções em salas e galerias dentro dos departamentos de ensino (MENDONÇA, 2017).

Este artigo traz como estudo de caso o Programa de Formação do Educativo do Museu de Arqueologia e Etnologia ${ }^{1}$ da Universidade de São Paulo (MAE-USP). O Programa está estruturado em três linhas de atuação: a formação e a sensibilização de jovens estudantes para o campo museal por meio das bolsas de estudos oferecidas pela USP; o estágio de observação da licenciatura, que contribui na formação de futuros profissionais da educação

1 O MAE é um dos quatro museus estatutários da Universidade de São Paulo, tem autonomia institucional e atua com o ensino, pesquisa e extensão. 
formal atentos às potencialidades dos museus; e a formação continuada de professores e professoras para a abordagem das temáticas da arqueologia e da etnologia em sala de aula. Esse Programa, assim como outros, reforça a compreensão de que os museus universitários desempenham um papel interno, com a comunidade acadêmica, e um outro externo, ao atuar de diferentes formas com a sociedade. Em comparação com os demais museus que não se inserem na esfera universitária, o viés formativo integrado e processual é um dos seus diferenciais e potência. Cabe destacar que museus que atuam fora da jurisdição das universidades também realizam excelentes trabalhos de formação, seja com públicos externos ou no âmbito profissional. O período analisado foi de 2012 a 2019, evidenciando o olhar técnico especializado de profissionais do MAE que estão na linha de frente de muitas ações do processo curatorial.

Os resultados da formação permanente realizada pelo Educativo se refletem na continuidade de parte desses bolsistas no campo profissional depois de formados(as); na ampliação do olhar de futuros professores e professoras para as potencialidades de uso cultural, social e pedagógico dos museus; para contribuir com a aplicação da Lei $n^{\circ}$ 11.645, de 2008, nas escolas; por fim, no alargamento e redesenho institucional do próprio Museu com base nas demandas das novas gerações. A reflexão está estruturada na apresentação geral do Educativo e na verticalização sobre o formato e o papel do Programa de Formação. Busca-se registrar essa história e contribuir com a fomentação de elos entre as diferentes gerações que passam pelo Museu.

\section{OS PROGRAMAS DO EDUCATIVO DO MAE-USP}

Em uma tarde de 2004, visitei ${ }^{2}$ pela primeira vez, como público espontâneo, o MAE-USP. Estava no primeiro ano do bacharelado em História, na Faculdade de Filosofia, Letras e Ciências Humanas (FFLCH) da USP, em 2004. Meu ônibus passava todos os dias em frente ao Museu, e eu havia criado a intenção de conhecê-lo, no movimento inerente a qualquer calouro ou caloura que passa a explorar o campus e tudo o que a Universidade pública pode oferecer.

2 Peço licença aos leitores e leitoras para apresentar essa experiência em primeira pessoa, pois evidencia o espaço de formação do MAE e a criação de vínculos entre profissionais e gerações. 
Esse foi o meu primeiro contato com um museu universitário. Passei por um processo de encantamento ao adentrar, por acaso, a exposição Formas de Humanidade ${ }^{3}$, que apresentava todas as áreas de pesquisa da instituição pelos eixos da diversidade, da temporalidade e da territorialidade (BRUNO, 1996). Ainda me lembro do impacto ao explorar o espaço expositivo e observar todas aquelas peças e informações. As lembranças das cores de cada módulo, as ilustrações feitas à mão, as gavetas que se abriam e mostravam mais objetos, e a infinidade de peças de distintas culturas me marcaram profundamente.

Posteriormente, percebi a existência das áreas da arqueologia, etnologia e museologia. Oriundo de escola pública, ao longo da minha vida havia visitado pouquíssimos museus e eles não faziam parte da minha realidade afetiva nem do meu repertório. Inicialmente, minha ideia era ser professor de História. Então conheci a Bolsa Trabalho da Coordenadoria de Assistência Social da USP (Coseas) e me candidatei a uma vaga de estágio no MAE. Entre 2005 e 2009, atuei como estagiário em alguns programas do Educativo, voltados para a aproximação da arqueologia e da etnologia com os públicos e recebi uma formação sólida dos educadores e educadoras ${ }^{4}$, profissionais do corpo técnico especializado da instituição e do corpo docente. Assim, meu interesse pelos museus cresceu e trabalhei, concomitantemente, em diferentes aparelhos culturais da cidade. Com o tempo, tornei-me arqueólogo, algo que não fazia parte do meu referencial de mundo, e hoje atuo em um museu universitário.

Parto dessa experiência pessoal, do impacto do primeiro museu universitário por mim visitado, para mostrar a importância desses locais para a formação e ampliação de trajetórias profissionais de jovens, sobretudo o público universitário, que tem a possibilidade de atuar em distintos programas nessas instituições. Outros colegas também tiveram seus percursos alterados por meio das vivências em estágios e em pesquisas nos museus da USP. Obviamente, visitar um museu universitário não é determinante, mas o acesso a ele pode reverberar de forma inesperada.

3 A exposição Formas de Humanidade ficou em cartaz entre 1995 e 2010. Abordava todas as áreas de pesquisa da instituição e oferecia ao público o contato com a arqueologia brasileira, a arqueologia do Mediterrâneo e Médio Oriente, a etnologia indígena, africana e afro-brasileira.

4 A bolsa trabalho era supervisionada e orientada pelo educador Camilo de Mello Vasconcellos e pelas educadoras Carla Gibertoni Carneiro e Judith Mader Elazari. O processo de formação da equipe de estagiários era idealizado, coordenado e implementado pela equipe técnica. 
As universidades produzem acervos constantemente e são espaços adequados para os museus, com a salvaguarda e a comunicação de distintas coleções e pesquisas. No contexto brasileiro, esses espaços são profundamente imbricados com o desenvolvimento da ciência no país, amplamente trabalhado pela literatura. Apesar de todos os esforços de seus profissionais, o contexto contemporâneo parece não ser muito esperançoso para o papel e lugar dos museus nas universidades, a exemplo dos trágicos incêndios do Museu Nacional e, mais recentemente, do Museu de História Natural da Universidade Federal de Minas Gerais. Entretanto, a casa das musas tem lócus privilegiado e potencial nesses territórios. Nesse sentido, o papel público dessas instituições e o oferecimento de programas direcionados à formação são cruciais para sua democratização e sustentabilidade ao longo do século XXI. A sociedade pode contribuir com a defesa desses locais somente se sentirem que pertencem a eles.

É preciso ressaltar que os museus universitários não são exclusivamente os únicos responsáveis pela formação de novos profissionais e da atuação com professores e professoras. No caso da cidade de São Paulo, por exemplo, outras instituições em outros regimes de gestão realizam trabalhos de excelência, como a Pinacoteca do Estado de São Paulo, a Fundação Bienal, o Museu de Arte Moderna, o Instituto Tomie Ohtake, entre muitos outros.

O compromisso contemporâneo do Educativo do MAE-USP se estabelece na contribuição da construção de uma sociedade democrática, plural, que respeita e fomenta a produção e o respeito das diferenças. O papel da área é criar encontros significativos entre pessoas, acervos, pesquisas e distintos repertórios, com foco na formação crítica do pensamento. A educação em museus não irá redimir os museus de seu passado colonial e classista (MENESES, 2000), mas esses espaços privilegiados devem ser transformados e apropriados por diferentes coletividades. O MAE-USP tem a possibilidade de se alimentar com pesquisas de ponta das três áreas do conhecimento e experimentar muitas estratégias práticas e de divulgação desses saberes com a sociedade. Nessa mesma direção, sua autonomia garante a possibilidade de atuar de forma crítica e independente a interesses do mercado cultural. 
Dada a tipologia de acervos ${ }^{5}$ salvaguardados no Museu, por excelência, a diferença cultural ao longo do tempo e do espaço é explorada, relacionada às histórias e ao presente das populações indígenas, africanas, afro-brasileira, além das populações do Mediterrâneo e do Médio Oriente. O Educativo do Museu ${ }^{6}$ é reconhecido por seus programas permanentes que estruturam as ações da área; sua história está relacionada com o surgimento da própria instituição e remonta há mais de 40 anos de ações continuadas. Desde trabalhos pioneiros no campo da musealização da arqueologia, realizados no antigo Instituto de Pré-História (BRUNO, 1984; BRUNO; VASCONCELLOS, 1989), às práticas educacionais com distintos segmentos de públicos do antigo Museu de Arqueologia e Etnologia (HIRATA, 1985), a atuação foi sendo aprimorada buscando responder aos desafios e perguntas do presente.

Essa história salvaguardada pelo Museu ${ }^{7}$ permite, de maneira ampla, destacar o protagonismo do corpo docente e dos educadores e educadoras na promoção de importantes debates do campo museal, arqueológico e antropológico ao longo de quatro décadas. Como exemplo, o uso da pedagogia do despertar ${ }^{8}$, afinada com as reflexões das ciências humanas e com a compreensão do documento material como fonte de análise histórica e antropológica (CARNEIRO, 2009, p.52); as discussões com ênfase no desenvolvimento de trabalhos educativos por meio da cultura material como produto e vetor de relações sociais (MENESES, 1983); o desenvolvimento de práticas precursoras da chamada educação patrimonial (HORTA; GRUNBERG; MONTEIRO, 1999), com enfoque no patrimônio cultural que ganhou fôlego no campo da arqueologia a partir dos anos 2000; a mobilização de conceitos de Paulo Freire no período de redemocratização,

5 O MAE-USP abriga acervos relacionados à arqueologia brasileira, arqueologia pré-colombiana, arqueologia do Mediterrâneo e Médio Oriente, etnologia brasileira, etnologia africana e afro-brasileira. 6 Internamente, o Educativo é conhecido como Seção Técnica de Educação para o Patrimônio (STEP), que faz parte da Divisão de Apoio à Pesquisa e Extensão (Dape), implantada em 2012 e que reuniu áreas técnicas referentes ao processo curatorial de salvaguarda (documentação e conservação) e comunicação (expografia e educação).

7 Toda documentação referente às ações educativas do Museu está salvaguardada na instituição, sendo composta por milhares de itens documentais que estruturam e apresentam a história do trabalho educativo da instituição.

8 A pedagogia do despertar foi desenvolvida pela francesa Francine Best, buscando promover uma experiência intelectual das ideias, conceitos esses inerentes à área das ciências humanas (CARNEIRO, 2009). 
em particular a empatia nos trabalhos educacionais com a consideração da realidade dos visitantes e do próprio museu (BRUNO, 2020).

A participação do Educativo no processo curatorial ${ }^{9}$, compreendido como um ciclo integrado de ações e procedimentos (MENESES, 1990), também é um diferencial do MAE, que inclusive o destaca em relação aos demais museus da USP. Por fim, a área esteve envolvida com a criação de programas específicos para atender às particularidades dos públicos, como ações pioneiras com idosos e com públicos em vulnerabilidade social, desde a década de 1990. Trata-se de um legado de práticas relacionadas à atuação dos(as) profissionais Maria Cristina Oliveira Bruno, Elaine Farias Veloso Hirata, Camilo de Mello Vasconcellos, Adriana Mortara Almeida, Denise Cristina Carminatti Peixoto Abeleira, Célia Maria Cristina Dermatini, Judith Mader Elazari, Carla Gibertoni Carneiro, entre outros. Como informa Martins (2011), são educadores e educadoras de museus responsáveis pela produção dos conteúdos da educação em museus, assim como sua recontextualização em cada instituição e prática.

Com as mudanças no campo museal e as mudanças internas na equipe do MAE, outras abordagens metodológicas vêm sendo exploradas pelo Educativo, como as discussões sobre a descolonização dos museus e a ocupação indígena nesses espaços (CURY, 2017, 2020; ROCA, 2015), sobre gênero e a abordagem queer no trabalho educativo, com intuito de promover narrativas menos androcêntrica e visões críticas sobre os processos de produção identitária (SILVA, 2019; WICHERS, 2018), entre muitas outras. Nesse sentido, a Política Nacional de Educação Museal ${ }^{10}$ (PNEM) (Ibram, 2018), criada mediante a atuação e militância de muitos colegas, apresenta uma direção de atuação para a área como ferramenta de luta.

9 O educativo de distintas instituições, atualmente e ao longo da história, infelizmente teve e tem papel coadjuvante dentro do processo curatorial, tendo a área se tornado uma tradutora das exposições e conceitos curatoriais para o público. Muitos movimentos de profissionais buscam romper esse lugar subalterno.

10 A educação museal é entendida por esse autor como um movimento político fundamental de educadores e educadoras por todo país no fortalecimento e reconhecimento de sua atuação, como uma diretriz. Configura uma grande conquista, especialmente em relação à PNEM, um conjunto de ações de muitas mãos que se torna uma política pública para área. A multiplicidade de experiências e práticas em torno da educação em museus, arte educação, mediação, entre muitas outras categorias, não pode ser aglutinada em um termo ou conceito sem que sua história e suas especificidades sejam achatadas. Essa reflexão adota o termo "educação museal", mas acredita e respeita no movimento nacional da educação museal. 
No momento, a instituição trabalha com cinco programas permanentes que estruturam a prática e têm objetivos e estratégias distintas. O Programa de Mediação, por exemplo, oferece visitas orientadas nas exposições temporárias em cartaz para grupos agendados, instituições de educação formal, ONGs e demais organizações.

O Programa de Formação, foco da reflexão deste artigo, atua em três eixos: a formação de bolsistas, os estágios de observação da licenciatura e o oferecimento de cursos para professores e professoras que procuram estreitar as relações das escolas com a atuação do Museu. O Programa de Recursos Pedagógicos desenvolve materiais educativos que são emprestados às escolas para o tratamento das temáticas da arqueologia e da etnologia (VASCONCELLOS, 2019). A experiência do MAE nesse sentido vem alcançando de forma ampla pessoas que, muitas vezes, não conseguem vir até o Museu.

O Programa de Acessibilidade, pautado pelas discussões sobre a promoção do acesso aos museus por distintas camadas da sociedade (SARRAF, 2013, 2018; TOJAL, 2015), desenvolve projetos direcionados especialmente para o público com deficiência visual (VASCONCELLOS et al., 2009), para moradores e moradoras da comunidade São Remo, vizinha à USP,

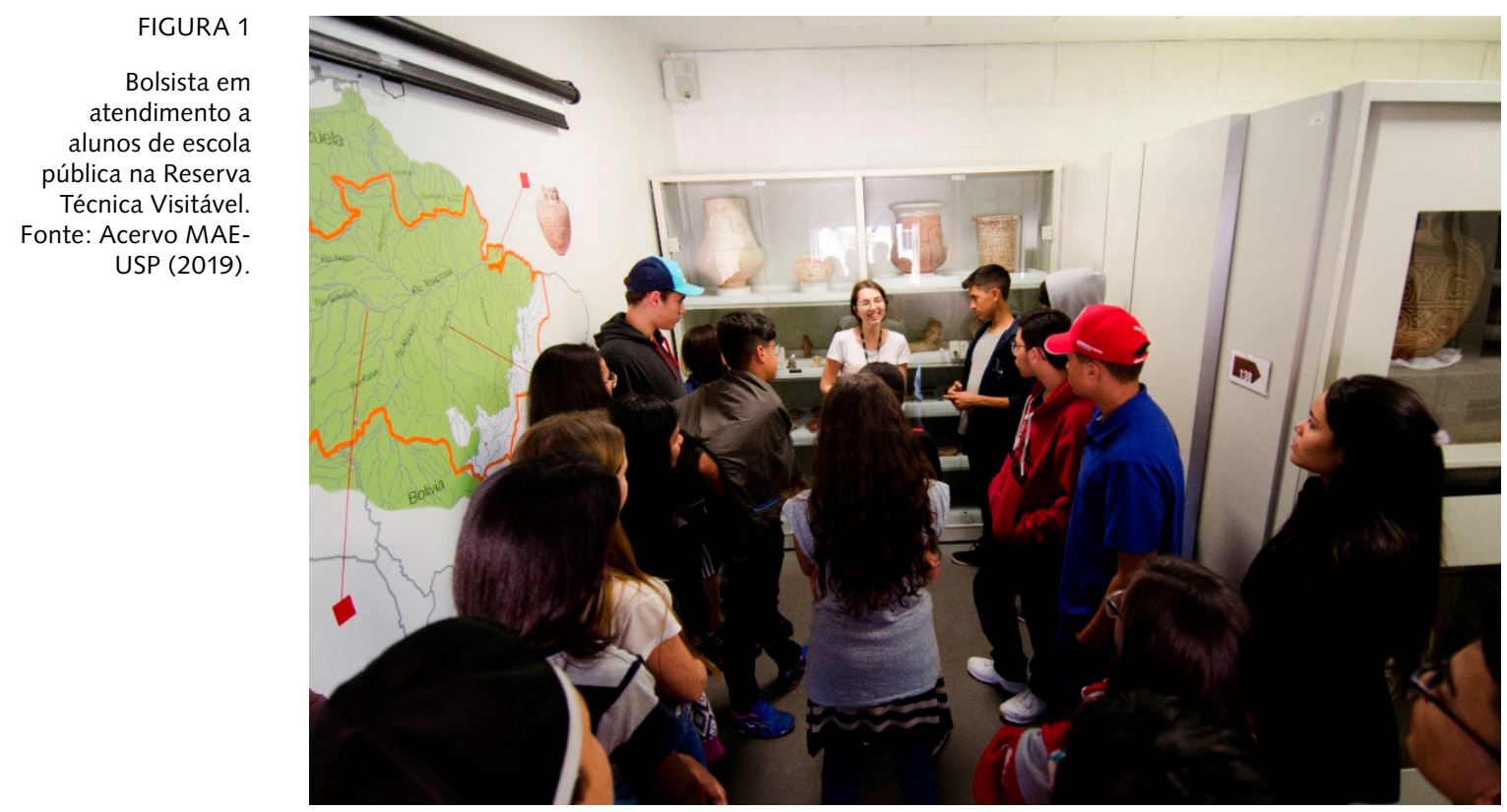


que se encontram em vulnerabilidade social (VASCONCELLOS, 2010; VASCONCELLOS; SILVA, 2017, 2018), além de oficinas para idosos e idosas (ELAZARI, 2009a, 2009b), sendo as duas últimas oferecidas desde a década de 1990. O Programa de Ações Extramuros desenvolve atividades fora do espaço do Museu mediante o oferecimento de palestras, cursos em outras instituições, assim como a participação dos educadores e educadoras em projetos de pesquisa acadêmica da arqueologia e de etnologia da instituição.

A estruturação das ações em Programas favorece uma maior articulação e organização institucional, assim como a preparação para algumas das demandas específicas de cada público, o que possibilita diálogos mais atentos. Entretanto é fundamental não perder de vista a discussão em torno do contrapúblico que, pela segmentação das ações direcionadas para escolas, professores(as), pessoas com necessidades especiais, entre muitos outros, estabelece uma forma de a instituição antever seus públicos e os achata em um modelo discursivo (SILVA, 2016). Dessa forma, não abre espaço para desvios e outras discussões que escapam da lógica institucional. Nesse sentido, é necessário que a área avalie periodicamente as ações para orientar a tomada de novas decisões e sua reformulação, assim como estar mais aberta à escuta efetiva dos(as) visitantes.

FIGURA 2
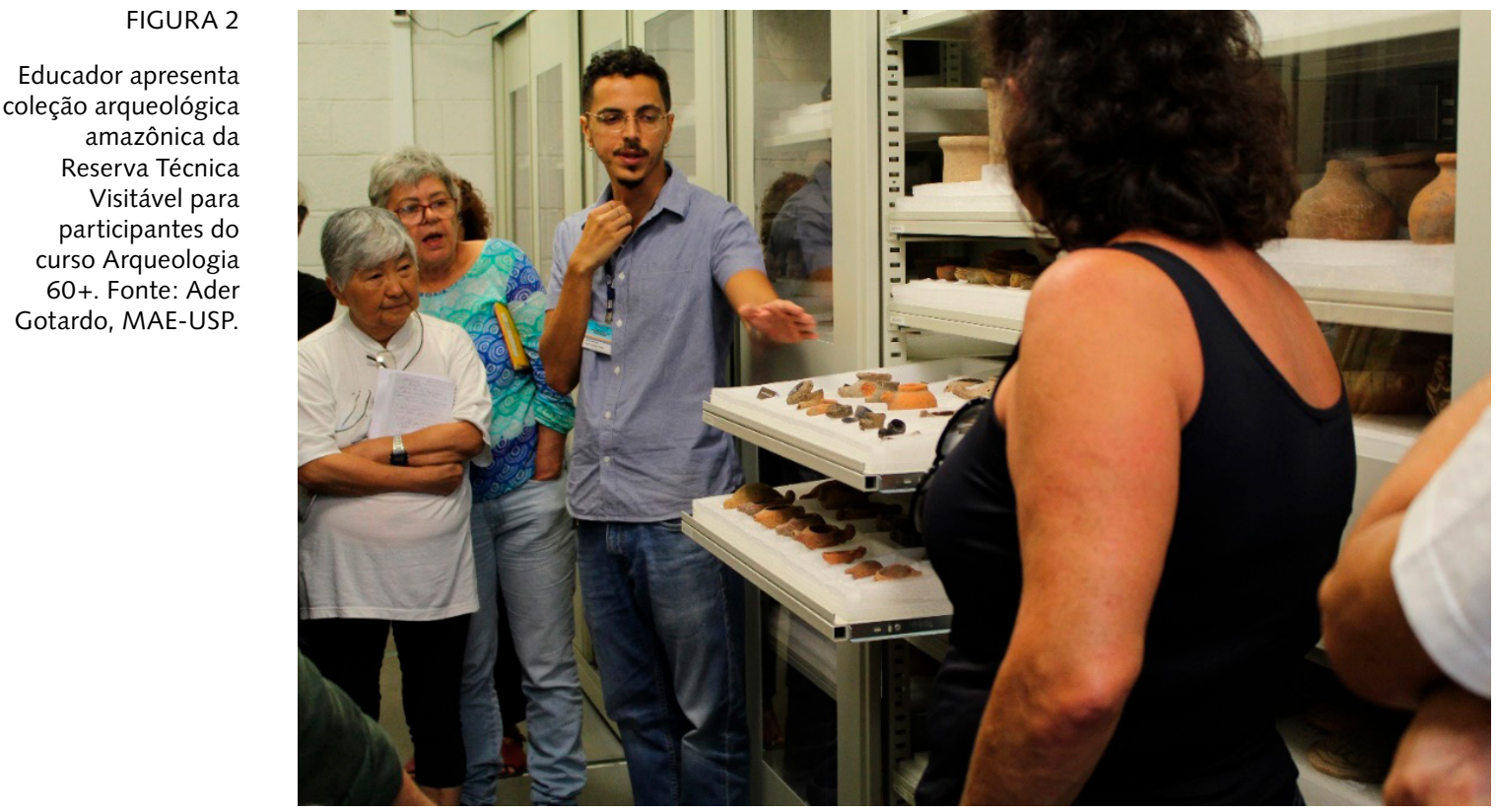
As ações educativas, construídas ao longo de décadas, contribuem para o engajamento social da instituição e reforçam seu compromisso com as pessoas e com a sociedade. Esse legado é a raiz da prática institucional que consolida sua identidade, princípios que são transformados pelos desafios colocados no presente. Uma maneira de manter esse fluxo de transformação é pela atuação, formação e escuta das novas gerações, pois elas ajudam a ampliar institucionalmente as práticas.

\section{FORMAÇÃO COM O EDUCATIVO, CONSTRUÇÃO DE UM CHÃO COMUM}

A discussão sobre formação de profissionais de museus ganhou força e visibilidade no Brasil com o avanço das políticas públicas para área, segundo Costa (2019), com a Política Nacional de Museus a partir de 2003; com a Política Nacional Setorial de Museus a partir de 2010; e, com a PNEM, a partir de 2017, cresce o oferecimento de cursos de museologia, o estímulo à profissionalização e formação permanente na área, a criação das Redes de Educadores Museais (REM), entre outras medidas. Entretanto, conforme a mesma autora, destaca-se a pouca presença de instâncias acadêmicas direcionadas para esse processo de formação da educação museal, sendo que os(as) jovens aprendem, sobretudo, a partir da prática dentro das instituições museológicas (COSTA, 2019). Não se pode perder de vista, também, décadas de experimentações e atuação dos museus brasileiros no que tange aos processos educacionais e de formação de profissionais para o campo.

A formação de futuros profissionais de museus na USP ocorre de forma diluída e a partir do interesse do(a) estudante. Em alguns departamentos, são oferecidas disciplinas que abordam ou tangenciam a educação em museus, principalmente na Escola de Comunicação e Artes (ECA), na Faculdade de Educação (FE), na Faculdade de Filosofia, Letras e Ciências Humanas (FFLCH), e nos quatro museus estatutários, entre outros. Ressalta-se que, independentemente do curso realizado, o(a) estudante tem possibilidade de se matricular em disciplinas em outras unidades de ensino - inclusive recomenda-se, dada a distribuição da grade dos cursos em disciplinas obrigatórias, optativas e eletivas, com carga de créditos correspondentes a cada uma. 
No caso do MAE, além de disciplinas específicas da graduação para as áreas de arqueologia e etnologia, atualmente, as que abordam o campo da educação em museus são Arqueologia; Etnologia e Museologia: Limites e Reciprocidades nos Museus Contemporâneos; e Museologia: Comunicação/ Educação, ministradas pela professora Maria Cristina Oliveira Bruno; Exposições Antropológicas, ministrada pela professora Marília Xavier Cury; e, especificamente voltada ao tema, a disciplina Educação Patrimonial, ministrada pelo professor Camilo de Mello Vasconcellos. O Museu também sedia o Programa de Pós-Graduação Interunidades em Museologia. Os(as) bolsistas, ao longo de sua trajetória, podem optar por cursar alguma dessas disciplinas para aprimorar sua formação.

Como já salientado, as bolsas e estágios são propulsores e mobilizadores para os(as) estudantes se aproximarem dos museus e da educação nesses locais. Dessa forma, reforça-se o argumento de que a formação de profissionais de museus e de educadores e educadoras ocorre a partir da prática. O programa de bolsas também permite a mobilidade dentro da universidade, que potencializa seu espaço de troca de conhecimento entre as áreas de humanas, exatas, biológicas e reforça o caráter interdisciplinar. As bolsas destinadas à graduação na USP se aprimoraram ao longo do tempo, sempre com enfoque no apoio socioeconômico e no desenvolvimento acadêmico. Nessa perspectiva, a Bolsa Trabalho $^{11}$ da Coseas, criada em 1989 e encerrada em 2008, teve papel importante na política da permanência estudantil. No período, essa modalidade poderia ser oferecida tanto pelo corpo docente como pelo corpo técnico especializado da USP. Ela foi substituída em $2008^{12}$ pelo Programa Aprender com Cultura e Extensão, criado junto à Pró-Reitoria de Cultura e Extensão Universitária (PRCEU), e, em 2015, novamente alterada pelo Programa Unificado de Bolsas (PUB), vinculado à Pró-Reitoria de Graduação, que passou a oferecer as bolsas nas três vertentes: ensino, pesquisa e extensão.

\footnotetext{
11 A Bolsa Trabalho da Coseas foi criada pela Portaria $\mathrm{n}^{\circ} 2.476$, de 1989 , sendo alterada pontualmente pelas Portarias no 2.612 , de 1990, e n ${ }^{\circ} 3.335$, de 2002. A remuneração era vinculada ao salário-mínimo vigente, que garantia o reajuste anual.

12 Em 2008, também foi regulamentada a lei federal que estruturou o oferecimento de estágios no país, passando o estágio a ser obrigatório e não obrigatório. O primeiro relaciona-se às atividades da grade curricular do curso de origem, como os estágios de observação de Licenciatura e Pedagogia, por exemplo; o segundo é voltado a ampliar a formação. A legislação prevê o pagamento de bolsaauxílio, auxílio-transporte e recesso remunerado.
} 
O oferecimento de bolsas de estudos e de estágios no MAE para estudantes de graduação acompanha a história institucional. Desde sua criação até os dias atuais, o Museu concede distintas possibilidades para o envolvimento de estudantes nas dimensões do ensino, pesquisa e extensão. Este artigo é focado em recorte específico, ao refletir sobre a formação de bolsistas e de estagiários(as) pelo Educativo do MAE. Outros setores e áreas do Museu também desenvolvem esse trabalho com excelência e ótimos resultados.

No caso do Educativo do MAE, atualmente, as Bolsas do PUB têm atuação efetiva dos educadores e das educadoras na estruturação, concepção e formação das novas gerações, sendo coordenadas pelo corpo docente ${ }^{13}$. Os(as) bolsistas atuam nos cinco Programas apresentados, por meio do acompanhamento das atividades realizadas pela equipe profissional do Museu, pela atuação nas atividades específicas e pela experimentação e elaboração de propostas a serem aplicadas com acompanhamento do corpo técnico.

A formação continuada oferecida pelo MAE-USP busca criar um chão comum, ancorado nos compromissos institucionais, nos desafios colocados pelo mundo contemporâneo e na escuta efetiva das novas gerações. Também almeja garantir o oferecimento de ações inclusivas e democráticas na promoção da diferença, e a possibilidade efetiva de diálogo com distintos repertórios. Semanalmente, todos(as) os(as) bolsistas participam de um espaço contínuo de aprendizado, que tem o objetivo de potencializar o papel pedagógico desse processo. Também se configura como um local de sociabilização dos(as) estudantes, oriundos(as) de distintas áreas, o que amplia a interdisciplinaridade e um amplo convívio com outras equipes da instituição. $\mathrm{O}$ único pré-requisito para se candidatar é ter disponibilidade para participar das reuniões semanais de formação. Esse espaço é o alicerce do trabalho e o local onde se amplia a troca de saberes entre técnicos, docentes e estudantes.

Nesse processo, são contempladas três grandes áreas - arqueologia, etnologia e museologia -, com enfoque nos temas da educação em museus, do patrimônio, da acessibilidade, da relação museu-escola, dos acervos da instituição, do processo curatorial, entre outros. A equipe debate os assuntos,

13 Especialmente por Camilo de Mello Vasconcellos, Maria Cristina Oliveira Bruno e Marília Xavier Cury. 
recebe convidados(as) e especialistas do Museu para trazerem contribuições ou mesmo participa de eventos acadêmicos e de outras instituições. $O$ fato de ser um museu universitário traz a facilidade de ter a contribuição do corpo docente nesse processo, assim como de estudantes de pós-graduação com seus temas de pesquisas, que podem ser facilmente acionados(as).

Para a formação de um bom educador ou educadora de museu, é fundamental o envolvimento prático com a área, mas também seu aprofundamento teórico. Destacam-se nesse processo as discussões realizadas pelo Educativo sobre a abordagem e desconstrução do imaginário escolar em torno dos grupos indígenas (VASCONCELLOS, 2015b); aproximações da educação em museus com a educação patrimonial (VASCONCELLOS, 2019); as especificidades da educação não formal (CAZELLI; VALENTE, 2019; MARANDINO, 2008); o histórico de ações e de práticas relacionadas ao educativo do Museu e de instituições correlatas (CARNEIRO, 2009; FLEMING; FLORENZANO, 2011; VASCONCELLOS, 2015a); o desenvolvimento de trabalhos colaborativos, pela perspectiva decolonial, com as populações indígenas (CURY, 2017, 2020; ROCA, 2015); o papel da museologia para a produção da noção de herança e de pertencimento (BRUNO, 2006); recentemente, abordagens de gênero e queer nas ações educacionais (SILVA, 2019; WICHERS, 2019), discussão das práticas libertadoras e antirracistas (HOOKS, 2013), entre muitas outras. Com os novos desafios impostos pelo isolamento social, em virtude da pandemia da Covid-19, a área tem explorado as discussões do engajamento digital e o oferecimento de ações a distância, como a Formação Aberta: Educação em Museus ${ }^{14}$, realizada no canal do YouTube do Museu, com participação de diferentes especialistas.

A formação continuada tem bases consolidadas e, todo ano, é reestruturada a partir de projetos, estando aberta aos novos rumos institucionais e às transformações da área. Com o lançamento da plataforma da exposição

\footnotetext{
14 Os temas desenvolvidos pelos encontros de formação aberta durante a pandemia até o momento foram: A musealização do patrimônio indígena - colaboração, autorrepresentação, repatriamento e outros temas para a descolonização; As coleções no MAE-USP: origens, trajetórias e caminhos futuros; Educação museal: dos caminhos de buscas metodológicas à função social dos museus; Os desafios da acessibilidade dos museus, antes, durante e depois da pandemia: um exercício de imaginar futuros possíveis; Museus de ciência e alfabetização científica; Bastidores e processos de elaboração de uma exposição em um Museu Universitário; e Matrizes Afro-brasileiras: aportes para uma museologia antirracista.
} 
e ação educativa "Resistência Já! Fortalecimento e união das culturas indígenas. Kaingang, Guarani Nhandewa e Terena”, em março de 2019, da qual o Educativo participou do processo curatorial desde o início, ampliou-se o compromisso com a descolonização das práticas institucionais e a promoção da autonarrativa indígena dentro do Museu. Um dos vários objetivos da exposição temporária foi deixar marcas permanentes nas equipes.

Em relação à formação de bolsistas para atuar na mediação dessa mostra, especificamente, implementou-se uma reflexão sobre as histórias de vida da equipe e como elas dialogam com as histórias indígenas. Essa estratégia viabiliza uma melhor compreensão sobre as diferenças que constituem as identidades e como podem ser mobilizadas no processo de mediação, respeitando o lugar de enunciação da fala indígena. Para respeitar o outro, é preciso entender o local que cada sujeito ocupa no mundo, lugar do grupo social ao qual pertence, além de entender como se tornar aliado da luta de outras populações minoritárias. Esse processo enriquecedor foi adotado como prática permanente no processo de formação. Foi humanizado o lócus social das bolsas, assim como o de cada membro, o que possibilitou que o trabalho de formação atente a algumas demandas trazidas pelos(as) estudantes.

A Universidade vem se transformando do ponto de vista do acesso e, mesmo sendo uma das últimas a adotar políticas afirmativas, já é possível perceber uma transformação significativa e positiva no quadro dos(as) estudantes. Esse processo, no entanto, ainda precisa se efetivar nas áreas técnicas e docente no que se refere aos marcadores de classe, raça, gênero e sexualidade para além da norma. Nesse sentido, há muitos desafios a superar. Segundo pesquisa realizada pelo Escritório USP Mulheres, $71 \%$ dos(as) estudantes consideram a USP machista; $64 \%$, racista; e $52 \%$, homo-lebo-transfóbico; 47\% passaram por algum tipo de violência ao longo de sua trajetória estudantil; e 89\% consideram a USP elitista (CASTRO, 2018). Além de oferecer espaços para formação profissional, é preciso assegurar o acolhimento dessa diversidade nas instituições para fomentar uma sociedade mais democrática. O trabalho de formação de bolsistas oferecido pelos museus e demais órgãos precisa olhar para as diferenças que constituem esses sujeitos para não os limitar a métricas e metas a serem cumpridas. Um caminho possível é ponderar os objetivos dos projetos das bolsas com as escutas das histórias de vida de cada participante. 
Se inicialmente a formação dos(as) bolsistas estava direcionada aos temas da educação em museus e das áreas específicas da instituição, recentemente foi necessário expandir para outras temáticas, como as relacionadas aos marcadores sociais da diferença, gênero, sexualidade, raça, classe e geração, especialmente a partir de abordagens que implementem práticas antirracistas, antissexistas, anticlassistas, entre outras. Essas são demandas das novas gerações de profissionais em processo de formação e da sociedade de modo geral, que reforçam o compromisso da instituição com o século XXI. Em 2018, foi realizada uma aproximação com o Núcleo de Estudos sobre os Marcadores Sociais da Diferença (Numas) do Departamento de Antropologia da FFLCH, por intermédio da professora Laura Moutinho e das pesquisadoras Paula Alegria e Thaís Tiriba, o que possibilitou uma formação geral sobre esses temas e apontou rotas de estudos a serem seguidas.

FIGURA 3

Indígena Susilene Kaingang, assistente de pajé, da TI Vanuíre, município de Arco-Íris (SP) realiza a formação da equipe de bolsistas na exposição "Resistência Já!". Fotografia do autor (2019)

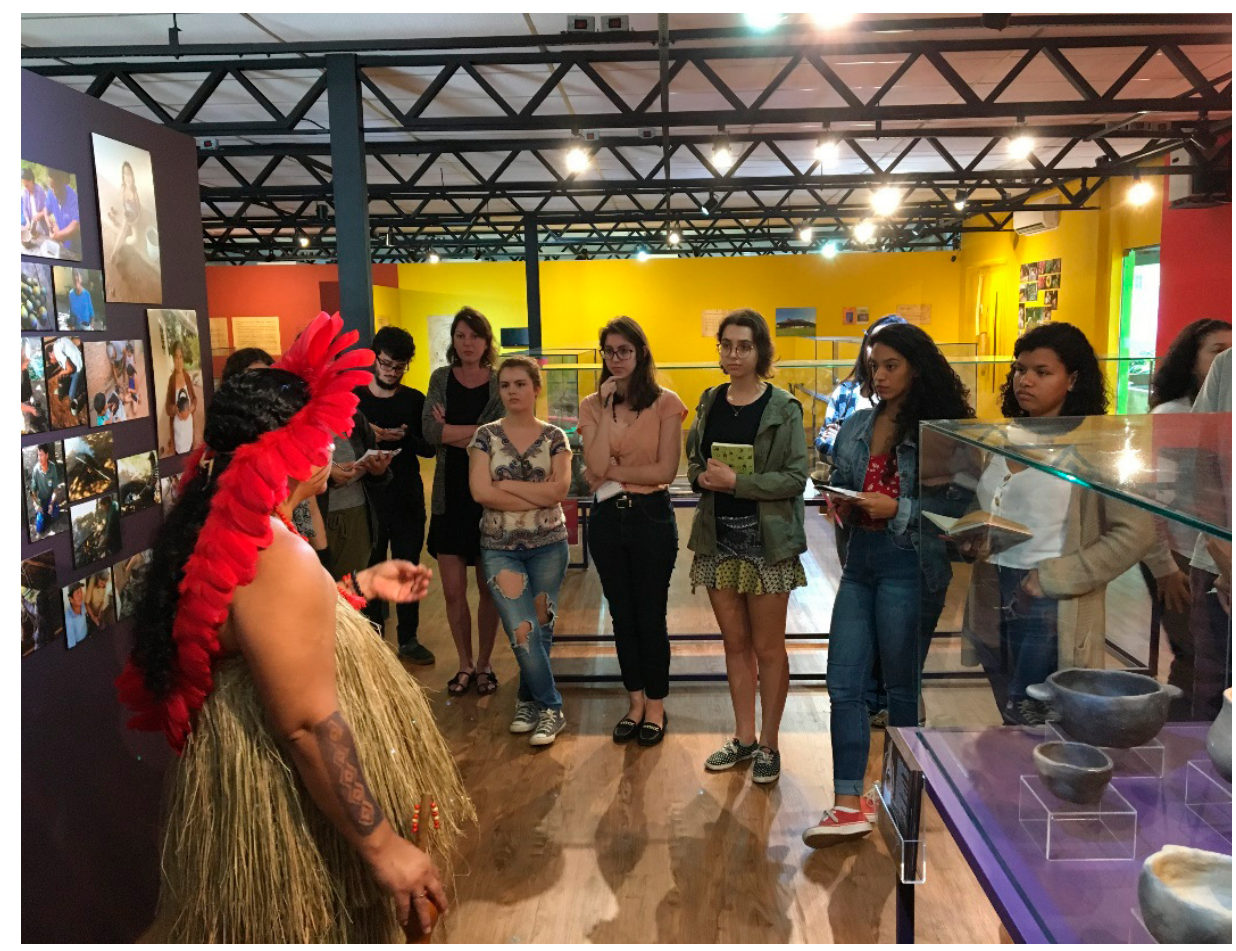


No período de 2012 a 2019, referente à gestão do autor deste artigo na formação do corpo de bolsistas, o Educativo contou 97 estudantes, perfazendo a média de 12 por ano. A maioria pertencia ao bacharelado em História $55 \%$, seguido por Ciências Sociais $9 \%$, Turismo $8 \%$ e Letras $7 \%{ }^{15}$. A média de permanência foi em torno de dois anos, sendo que o PUB permite ficar até quatro anos. Do total de 97 bolsas, 19 estudantes não completaram o ciclo e solicitaram o desligamento antes do prazo, por mudança para outra bolsa mais próxima aos seus interesses pessoais e do curso de origem; para realizar iniciação científica; iniciaram estágio; realizaram intercâmbio, entre outros motivos. Um dos aspectos que surge em relação à formação dos(as) bolsistas é seu caráter transitório nas instituições. Eles(as) ingressam no programa muitas vezes no início da graduação e, ao longo do período da bolsa, adentram o campo da educação em museus e aí se desenvolvem. Quando estão em um momento de domínio do trabalho, desligam-se em busca de novos horizontes profissionais ou com o término dos contratos ${ }^{16}$.

Esse é um dos papéis estruturantes da USP e dos museus universitários: contribuir para a formação das novas gerações. O trabalho tem de estar direcionado para essa abordagem e para o apoio constante a novos educadores e educadoras. A equipe de bolsistas não substitui a equipe técnica especializada, porém o problema se amplia com a redução de funcionários efetivos e com a falta de renovação dos quadros técnicos fixos da universidade. Mesmo nesse cenário, as instituições não podem perder de vista que a função primeira das bolsas está direcionada ao desenvolvimento pessoal e profissional. Ao longo dessas décadas, muitos bolsistas do Educativo do Museu seguiram atuando como profissionais da arqueologia, da etnologia, como docentes em universidades, educadores e educadoras de museus. Nessa direção, existe um vasto campo de pesquisa a ser desenvolvido sobre os profissionais egressas do MAE e os impactos qualitativos dessas bolsas.

No caso do Museu de Arte Contemporânea da USP, que também atua com oferecimento de bolsas e estágios, segundo Francoio et al. (2010), a formação de bolsistas promove uma série de benefícios no curto prazo, como

15 Nesse período, estudantes de Geografia, Educomunicação, Terapia Ocupacional, Pedagogia, Administração, Artes, Ciências da Natureza, Geociências, Jornalismo, Oceanografia e Matemática também passaram pelo Educativo do Museu.

16 As bolsas do Programa Unificado de Bolsas da Universidade permitem até quatro renovações. 
aquisição de novos conhecimentos e contato com artistas; compreensão dos diferentes formatos de visitas para atender às necessidades de cada grupo; vivência do espaço de cidadania do Museu ao promover o acesso à cultura de forma gratuita, entre outros. Os resultados dos trabalhos oferecidos pelos museus são transformadores.

Nesses programas os(as) estudantes não somente observam o trabalho, mas, a partir do momento que se sentem à vontade, passam a conduzir determinadas ações, como acolhimento de grupos, mediação nas exposições e elaboração e aplicação de oficinas, sempre com processo de avaliação e discussão posterior com a equipe técnica. Os benefícios identificados são o contato com a arqueologia e museologia durante a graduação na USP, pois a universidade não oferece bacharelado nessas áreas, somente pós-graduação; o exercício da interdisciplinaridade entre as disciplinas da graduação de origem dos(as) bolsistas com as áreas do Museu; a dimensão prática de atuação da área de humanidades por meio das ações de extensão com diferentes públicos; reforço de uma visão social com a atuação nos programas do Educativo; maior contato com o corpo técnico especializado e docente da universidade, devido à escala do MAE; o desenvolvimento profissional desses jovens, entre muitos outros.

Diante da potencialidade dos museus universitários no oferecimento de bolsas e estágios para colaborar com a formação profissional, o campo da educação em museus, especificamente, apresenta outros desafios. Ressalta-se que profissionais formados(as) não se veem atuando durante muito tempo na área como educadores e educadoras de museus. Há muitos fatores que contribuem para essa evasão, especialmente quando são observadas, em muitos dos museus que estão fora da universidade, dificuldades como baixos salários, o não reconhecimento legal da profissão, a necessidade de trabalhar em mais de uma instituição para complementar a renda, entre outros fatores (BIELLA; CARNEIRO; SILVA, 2018).

A instabilidade do campo da educação em museus ficou evidente com o momento da pandemia da Covid-19, com a suspensão de contratos e demissão de educadores e educadoras em todo país (COMITÊ PARA EDUCAÇÃO E AÇÃO CULTURAL DO CONSELHO INTERNACIONAL DE MUSEUS DO BRASIL; REDE DE EDUCADORES EM MUSEUS DO BRASIL, 2020). Ao mesmo tempo que os museus, por excelência, são 
espaços destinados à educação, os educativos são os primeiros a serem desestruturados em momentos de crise. Nessa perspectiva, cabe ressaltar o movimento mundial para redefinir o conceito de museu, que está sendo realizado, desde 2016, pelo International Council of Museums (Icom), no qual, em algumas propostas, o termo educação não foi contemplado. Ou seja, o caráter educacional, reconhecidamente dos museus, não é algo garantido no século XXI do entretenimento e do consumo da cultura. Gerou-se uma grande mobilização em 2019, particularmente nos museus da América Latina, em função dos desafios regionais e da importância da manutenção dessa dimensão nesses contextos de desigualdade social. Fica evidente a imbricada relação entre educação e museus, assim como a fragilidade do campo educacional mediante o abismo entre discurso e prática implementado pelas instituições ${ }^{17}$.

O Estágio de Licenciatura do Educativo do MAE-USP, por sua vez, proporciona aos estudantes de diferentes cursos de licenciatura da USP e de outras universidades a possibilidade de cumprir as horas dos estágios obrigatórios no Museu. O programa tem o mínimo de 42 horas, que podem ser ampliadas de acordo com as necessidades pessoais e de cada departamento. O objetivo é sensibilizar futuros profissionais que atuarão na rede formal de ensino sobre os usos pedagógicos, culturais e sociais dos museus. A cada ano, docentes dos cursos de licenciatura da USP e de outras instituições têm se sensibilizado e reconhecido o potencial da formação de seus estudantes nos espaços de educação não formal. Assim, a procura pelos estágios de observação tem sido crescente, em particular pelas licenciaturas dos cursos de História e Sociologia.

O curso fornece conceitos estruturantes das áreas da museologia, arqueologia e etnologia, com enfoque na cultura material, no patrimônio e sobre o papel e as especificidades da educação não formal. Nesse sentido, os(as) participantes acompanham o desenvolvimento de todos os programas

17 É necessário fazer uma ressalva em relação aos museus não universitários e instituições culturais e, a partir do exemplo da cidade de São Paulo, outros espaços também promovem programas de estágios. Destaca-se o trabalho realizado pelos museus ligados à Secretaria de Cultura e Economia Criativa do Governo do Estado de São Paulo, e instituições como Fundação Bienal, Instituto Tomie Ohtake. A Fundação Bienal, com a implantação do Educativo Permanente em 2011, com a coordenação da Stela Barbiere, ampliou o foco na formação continuada de profissionais e estudantes. 
e analisam os recursos pedagógicos que o Museu oferece para as escolas. As horas estão organizadas em reuniões presenciais com a equipe de educadores e educadoras; observação do atendimento das escolas no Museu e da formação de professores e professoras; por fim, elaboram e apresentam uma sequência didática para ser aplicada a uma turma específica do ensino formal, com o recorte no uso do Museu.

Os resultados são significativos e se materializam na compreensão da função dos educativos dos museus e da escola na elaboração de um trabalho conjunto, principalmente sobre os papéis dos professores e professoras em visita orientada a uma exposição. É importante esse preparo prévio das escolas às visitas aos museus, assim como os desdobramentos do pós-visita. Cabe destacar que esse programa foi iniciado pela educadora Judith Mader Elazari nos anos 2000, atualmente coordenado pela educadora Carla Gibertoni Carneiro e pelo autor deste artigo.

Os benefícios institucionais dessa ação se refletem no retorno dos jovens ao Museu quando passam a atuar na rede de ensino. Muitos procuram o Educativo para trazer seus alunos e alunas, assim como para retirar os materiais educativos emprestados e buscar aproximações pedagógicas com o MAE-USP. Esse trabalho se volta para o Educativo do MAE, mas prepara o(a) profissional para o uso educacional de outros museus. Nesse sentido, são indicadas as orientações para que conheçam o projeto pedagógico dos museus antes de levarem suas turmas; buscarem os materiais didáticos produzidos pelos espaços; estruturem a visita antes, durante e depois para que se crie um sentido pedagógico para a saída da escola; e para não escolarizar os museus, entendendo que são espaços onde se aprende de outras formas. Por ano, a média de estudantes que desenvolve seus estágios de observação no Museu varia entre 30 e 40 participantes.

Por fim, outra ação referente ao Programa é a formação de professores e professoras, ação direcionada para profissionais que já atuam na rede e em instituições correlatas. O Museu desenvolve esse trabalho há quatro décadas, com a promoção de uma abordagem qualificada das temáticas arqueológicas e antropológicas para serem aplicadas em sala de aula. Uma parcela considerável de profissionais não teve em sua trajetória o contato com esses assuntos, especialmente no que concerne à obrigatoriedade do tema "História e Cultura Afro-Brasileira e Indígena" na escola, com a Lei 
$\mathrm{n}^{\circ}$ 11.645, de 2008. Esse cenário tem mudado beneficamente e há muitas pessoas engajadas com o ensino de qualidade, que buscam nas instituições não formais a complementaridade de sua formação. Cabe destacar que cada vez mais os livros didáticos abordam esses assuntos, mas de maneira superficial e, muitas vezes, de maneira estereotipada.

Boa parte desses cursos está estruturada mediante os recursos pedagógicos que o Museu oferece e que, após a formação, podem ser emprestados e usados em sala de aula. Todos são organizados com coleções didáticas arqueológicas e etnográficas e promovem uma aula interativa com o uso da cultura material e de sua investigação. Nessa direção, os objetos podem ser mobilizados como vetores de relações sociais, instigar o olhar crítico e investigativo para a realidade, além de levantar reflexões sobre o passado e o presente. Segundo Vasconcellos (2019), recursos pedagógicos facilitam o processo de aprendizagem, despertam o interesse e a experimentação por meio da manipulação de diversos suportes, que contribui para a vivência de experiências significativas. Os materiais que compõem esses recursos são: 0 Kit Educativo de Arqueologia e Etnologia, o Kit Educativo de Arqueologia do Mediterrâneo, o Kit de Objetos Infantis Indígenas e as Maquetes Táteis de Arqueologia Brasileira.

Anualmente, em média mil professores e professoras participam das formações; em 2019, 1.261 profissionais participaram, com número superior de profissionais da rede pública de ensino. Por sua vez, o empréstimo dos materiais levados até as escolas, por ano, alcança em torno de dez mil estudantes. Em 2019, esse número foi de 12.719 estudantes. Nesse momento de pandemia, busca-se adaptar os materiais para o espaço digital, assim como estruturar o trabalho de formação a distância.

O recorte destinado ao Programa de Formação do MAE-USP, estruturado nessas três frentes de atuação, evidencia o compromisso da instituição com o espaço acadêmico de formação e o aprimoramento profissional, assim como com a sociedade de modo geral com o diálogo constante com professores e professoras. São ações que contribuem para a renovação da área e a sensibilização para o potencial de uso profissional e pedagógico dos espaços museais. 


\section{CONSIDERAÇÕES FINAIS}

Muitos(as) profissionais que trabalham atualmente em distintos campos da área cultural, educacional e docente começaram sua trajetória em museus universitários. Ainda é necessário mapear essas histórias com um olhar qualitativo para a importância desses espaços para a formação profissional. Em relação à transformação social e de acesso que se vê nas universidades, os museus, por excelência, podem desempenhar um papel primordial no acolhimento dessas diferenças e na inserção afetiva desses indivíduos na vida universitária e na própria ciência. Os estudos em torno da formação de educadores e educadoras de museus, arte-educadores, mediadores, entre outras denominações podem ampliar a discussão e os dados a partir de pesquisas nas instituições que oferecem esse serviço, especialmente nos museus universitários.

Todos os museus são locais destinados à educação, à transformação pessoal, coletiva e social. No caso dos museus universitários, a dimensão educativa e de formação se potencializa por meio da mobilização e da dinâmica implementada pelas pesquisas e por estarem inseridos no território das universidades que prezam pelo ensino, pela pesquisa e extensão. Nesse caso, o papel na formação e na sensibilização de jovens ingressantes dos mais diferentes cursos de graduação para o campo museal possibilita a manutenção e renovação da área. Da mesma forma, o incentivo para o campo museal também fortalece sua sustentabilidade no século XXI. O questionamento atual sobre a manutenção dos museus pelas universidades não leva em consideração uma série de indicadores que demonstra sua qualidade para a vida acadêmica e para atuação na sociedade de forma mais ampla. Da mesma maneira, são esquecidas as imbricadas relações históricas entre os museus e o desenvolvimento da ciência no país.

O quadro técnico especializado dessas instituições é altamente qualificado e, em muitos casos, são décadas de dedicação a determinado segmento da cadeia operatória museológica. No caso dos processos de formação das novas gerações, além de contarem com o campo docente, podem conviver e atuar diariamente com especialistas que dominam plenamente suas funções do ponto de vista da teoria e da prática - experiência específica que, muitas vezes, museus que não estão inseridos nas universidades não contam, dada a alta rotatividade das equipes, a prestações pontuais de 
serviços etc., no âmbito dos modelos de iniciativa público-privada. Os(as) bolsistas vivenciam o ensino no Museu pela apropriação do conhecimento produzido, ao cursar disciplinas optativas eletivas que versam sobre as três grandes áreas da instituição; também podem se envolver com as pesquisas e contribuir com a produção de novos conhecimento; e, por fim, intervêm na sociedade pelas ações de extensão que promovem processos educativos, culturais e científicos.

Dadas as multiplicidades de formatos de museus universitários pelo país, desde coleções em departamentos a organizações que desempenham todas as funções museais, o contato com os acervos e com a pesquisa contribui para consolidar posturas preservacionistas, patrimoniais, culturais e sociais em torno do patrimônio cultural. Da mesma forma, é nesses museus que parcelas distintas da sociedade conseguem romper os muros de classe, raça e gênero com seus primeiros estágios e bolsas, especialmente nas universidades, no desenvolvimento das ações de extensão. Ou seja, seus corpos passam a se sentir mais acolhidos no espaço universitário e, consequentemente, no universo do trabalho.

Espera-se que esse ciclo e processo constante de formação continuem ao longo das décadas e que os espaços públicos dos museus universitários possam cumprir suas funções na construção de um país mais democrático, possibilitando o acesso de novas camadas sociais para esses locais historicamente elitizados.

\section{REFERÊNCIAS}

BIELLA, Andrea Amaral; CARNEIRO, Carla Gibertoni; SILVA, Maurício André da. GT 2 - Formação de educadores de museus. In: MARANDINO, Martha. Seminário educação e museus: síntese dos grupos de trabalho. São Paulo: FEUSP, 2018. p. 11-14.

BRUNO, Maria Cristina Oliveira. Museu do Instituto de Pré-História: um museu a serviço da pesquisa científica. Dissertação (Mestrado) - Faculdade de Filosofia Letras e Ciências Humanas, Universidade de São Paulo, São Paulo, 1984.

BRUNO, Maria Cristina Oliveira; VASCONCELLOS, Camilo de Mello. A proposta educativa do Museu de Pré-História Paulo Duarte. Revista de Pré-História, n. 7, p. 161-189, 1989.

BRUNO, Maria Cristina Oliveira. Museologia e comunicação. Lisboa: Universidade Lusófona de Humanidades e Tecnologias, 1996.

BRUNO, Maria Cristina Oliveira. Museus e pedagogia museológica: os caminhos para a administração dos indicadores da memória. In: BRUNO, Maria Cristina Oliveira. As várias faces do patrimônio. [S. l: s. n.], 2006. 
BRUNO, Maria Cristina Oliveira. Educação museal: dos caminhos de buscas metodológicas à função social dos museus. YouTube MAE-USP, 2020. Disponível em: https://www.youtube. com/watch? $=q$ Puitm2ACVo\&t=2306s . Acesso em: 11 nov. 2020.

CARNEIRO, Carla Gibertoni. Ações educacionais no contexto da arqueologia preventiva: uma proposta para a Amazônia. Tese (Doutorado em Arqueologia) - Museu de Arqueologia e Etnologia, Universidade de São Paulo, São Paulo, 2009. DOI: 10.11606/T.71.2009.tde-28082009-100307 .

CASTRO, Mariangela. Para mais da metade dos estudantes, USP é machista e racista. Jornal da USP, São Paulo, 27 jun. 2018. Disponível em: https://jornal.usp.br/universidade/para-mais-dametade-dos-estudantes-usp-e-machista-e-racista/. Acesso em: 10 jun. 2020.

CAZELLI, Sibele; VALENTE, Maria Esther. Incursões sobre os termos e conceitos da educação museal. Revista Docência e Cibercultura, v. 3, n. 2, p. 18-40, set. 2019. DOI: https://doi. org/10.12957/redoc.2019.40729.

\section{COMITÊ PARA EDUCAÇÃO E AÇÃO CULTURAL DO CONSELHO INTERNACIONAL DE MUSEUS DO BRASIL; REDE DE EDUCADORES EM MUSEUS DO BRASIL. Carta Aberta dos educadores museais brasileiros sobre os efeitos da Pandemia de Covid-19 na educação museal no Brasil. 2020. Disponível em: http://www.Icom.org.br/files/Carta_Aberta_e_ Recomenda\% 3 \% $\%$ A7\% 3 \% B5es_para_Educa\% $\mathrm{C}_{3} \% \mathrm{~A}_{7} \% \mathrm{C}_{3} \% \mathrm{~A}_{30}$ _Museal_no_Brasil.pdf. Acesso em: 30 jun. 2020 .}

COSTA, Andréa Fernandes. A formação inicial e continuada de educadores museais: projeto em construção. Revista Docência e Cibercultura, [S.1.], v. 3, n. 2, p. 67-89, set. 2019. DOI: https:// doi.org/10.12957/redoc.2019.44693.

CURY, Marilia Xavier. Lições indígenas para a descolonização dos museus: processos comunicacionais em discussão. Cadernos CIMEAC, v. 7, n. 1, p. 184-211, jul. 2017. DOI: https:// doi.org/10.18554/cimeac.v7i1.2199 .

CURY, Marília Xavier. Metamuseologia: reflexividade sobre a tríade musealia, musealidade e musealização, museus etnográficos e participação indígena. Museologia \& Interdisciplinaridade, v. 9, n. 17, p. 129-146, 17 maio 2020. DOI: https://doi.org/10.26512/ museologia.v9i17.2948o.

ELAZARI, Judith Mader. Ação educativa em museus: a terceira idade construindo conhecimentos a partir de objetos no MAE/USP. Revista do Museu de Arqueologia e Etnologia, São Paulo, n. 19, p. 337-354, 2009a. DOI: https://doi.org/10.116o6/issn.2448-1750. revmae.2009.89893.

ELAZARI, Judith Mader. Encontro com idosos: escavando a memória a partir de objetos. In: PARK, Margareth Brandini; GROPPO, Luis Antônio (Org.). Educação e velhice. Holambra: [s.n.], 2009b. p. 93-105.

FLEMING, Maria Isabel D’Agostino; FLORENZANO, Maria Beatriz Borba. Trajetória e perspectivas do Museu de Arqueologia e Etnologia da USP (1964-2011). Estudos Avançados, v. 25, n. 73, p. 217-228, 1 jan. 2011. DOI: https://doi.org/10.159o/So103-40142011000300024 .

FRANCOIO, Maria Angela et al. Formação de bolsistas: Divisão Técnico-Científica de Educação e Arte do MAC-USP. Revista de Cultura e Extensão USP, v. 3, p. 7-13, 1 maio 2010.DOI: https://doi.org/10.11606/issn.2316-906o.v3iop7-13.

HIRATA, Elaine Farias Veloso. Relato das experiências educacionais do MAE: 1981-1982. Dédalo, São Paulo, n. 24, p. 11-20, 1985. 
HOOKS, Bell. Ensinando a transgredir: a educação como prática da liberdade. São Paulo: Martins Fontes, 2013.

HORTA, Maria de Lourdes Parreiras; GRUNBERG, Evelina; MONTEIRO, Adriane Queiroz. Guia básico de educação patrimonial. Brasília: Iphan: Museu Imperial, 1999.

INSTITUTO BRASILEIRO DE MUSEUS. Caderno da Política Nacional de Educação Museal. Brasília, DF: IBRAM, 2018. 132p. Disponível em: https://www.museus.gov.br/wp-content/ uploads/2018/o6/Caderno-da-PNEM.pdf . Acesso em: 5 jun. 2020

MARANDINO, Marta (Org.). Educação em museus: a mediação em foco. São Paulo: Geenf; FEUSP, 2008. 48 p.

MARTINS, Luciana Conrado. A constituição da educação em museus: o funcionamento do dispositivo pedagógico por meio de um estudo comparativo entre museus de artes plásticas, ciências humanas e tecnologia. Tese (Doutorado em Educação). Faculdade de Educação da Universidade de São Paulo, 2011. DOI:

10.11606/T.48.2011.tde-04072011-151245.

MENDONÇA, Lúcia Glicério. Museus universitários e modernidade líquida: compromissos, desafios e tendências (um estudo sob a perspectiva da Teoria Ator-Rede, Brasil e Portugal). Tese (Doutorado em Museologia) - Universidade do Porto, Faculdade de Letras, Porto, 2017.

MENESES, Ulpiano Toledo Bezerra de. A cultura material no estudo das sociedades antigas. Revista de História, São Paulo, n. 115, p. 103-117, dez. 1983. DOI: https://doi.org/10.11606/ issn.2316-9141.voi115p103-117 .

MENESES, Ulpiano Toledo Bezerra de. Plano Diretor (1990-1995). São Paulo: Museu Paulista, 1990.

MENESES, Ulpiano Toledo Bezerra de. Educação e museus: sedução, riscos e ilusões. Ciências \& Letras, Porto Alegre, n. 27, p. 91-101, 2000.

ROCA, Andrea. Acerca dos processos de indigenização dos museus: uma análise comparativa. Mana, Rio de Janeiro, v. 21, n. 1, p. 123-156, 2015. DOI: https://doi.org/10.159o/o10493132015V21n1p123.

SARRAF, Viviane Panelli. A comunicação dos cinco sentidos nos espaços culturais. Tese (Doutorado em Ciências) - Pontifícia Universidade Católica de São Paulo, São Paulo, 2013.

SARRAF, Viviane Panelli. Acessibilidade cultural para pessoas com deficiência - benefícios para todos. Revista do Centro de Pesquisa e Formação, n. 6, v. 1, p. 23-43, 2018.

SILVA, Maurício André da. Diálogos orientados/desorientados pela teoria queer. Revista Arqueologia Pública, v. 13, n. 1[22], p. 218- 237, 2 jul. 2019. DOI: https://doi.org/10.20396/rap. v13i1.865476o .

SILVA, Wandré. Contrapúblicos: o paradoxo e o paradigma. Relato sobre a mesa Públicos e Contrapúblicos. Brasília, DF: Memorial Darcy Ribeiro. Fórum Permanente de Museus, 23 de nov. 2016. Disponível em: http://www.forumpermanente.org/event_pres/encontros/encontrosde-mediacao-na-arte-contemporanea-a-atuacao-dos-publicos/relatos-criticos/relato-criticopublicos-e-contrapublicos. Acesso em: 3 jun. 2020. 
TOJAL, Amanda Pinto da Fonseca. Política de acessibilidade comunicacional em museus: para quê e para quem? Revista Museologia \& Interdisciplinaridade, v. 4, p. 190-202, 2015. DOI: https://doi.org/10.26512/museologia.v4i7.16779.

VASCONCELLOS, Camilo de Mello. O papel social e educacional dos museus: um estudo de caso do projeto girassol do Museu de Arqueologia e Etnologia da USP. In: NASCIMENTO, Silvania do; BOSSLER, Ana Paula (Org.). Museu e escola: isso me lembra uma história. Belo Horizonte: UFMG, 2010. p. 1-13.

VASCONCELLOS, Camilo de Mello. Las singularidades de los museos universitarios. Revista Códice Boletin Científico y Cultural del Museo Universitario de la Universidad de Antioquia, v. 28, p. 26-39, 2015a.

VASCONCELLOS, Camilo de Mello. O imaginário sobre o indígena: uma experiência de aprendizagem significativa no Museu de Arqueologia e Etnologia da USP. Museologia \& Interdisciplinaridade, v. 4, n. 7, p. 224-244, 3 nov. 2015b. DOI: https://doi.org/10.26512/ museologia.v4i7.16781 .

VASCONCELLOS, Camilo de Mello. Arqueologia e educação patrimonial: a experiência do MAE-USP. Revista CPC, v. 14, n. 27, esp., p. 255-279, 30 ago. 2019. DOI: https://doi.org/10.11606/ issn.1980-4466.v14i27espp255-279 .

VASCONCELLOS, Camilo de Mello et al. O Museu de Arqueologia e Etnologia da USP e o público especial. São Paulo: MAE-USP; Fundação Dorina Nowill para Cegos, 2009.

VASCONCELLOS, Camilo de Mello; SILVA, Maurício André. A comunidade, a Universidade e a cidade de São Paulo por meio do olhar das crianças da São Remo: o trabalho socioeducativo do Museu de Arqueologia e Etnologia da Universidade de São Paulo. In: PERALTA, Romina; LOZA, Alicia (Org.). Museos y archivos universitarios: educación, accesibilidad e inclusión, un debate necesario. La Plata: Universidad de la Plata, 2017. p. 196-206.

VASCONCELLOS, Camilo de Mello; SILVA, Maurício André da. A mediação comunitária colaborativa: novas perspectivas para educação em museus. ETD - Educação Temática Digital, v. 20, n. 3, p. 623-639, 16 jul. 2018. DOI: https://doi.org/10.20396/etd.v20i3.8651713 .

WICHERS, Camila A. de Moraes. Museologia, feminismo e suas ondas de renovação. Museologia \& Interdisciplinaridade, v. 7, n. 13, p. 138-154, 28 maio 2018. DOI: https://doi. org/10.26512/museologia.v7i13.17781 .

Agradecimento a todos(as) os(as) bolsistas que passaram pelo Educativo, que ajudam arejar e renovar o campo a partir de seus anseios e urgências. Ao corpo docente do Museu, especialmente aos professores e professoras Camilo de Mello Vasconcellos, Maria Cristina Oliveira Bruno e Marília Xavier Cury, pela parceria e confiança em nosso trabalho, e à minha colega de área, Carla Gibertoni Carneiro.

\section{(co) EY-No-si}

